\title{
IMPACT OF GAMMA RADIATION OF PEEK ON ITS TRIBOLOGICAL PROPERTIES
}

\begin{abstract}
A. Niemiec*
Abstract: The radiation can bring changes in mechanical, tribological, thermal properties and in chemical, physical states. It was found that the modification through irradiation entailed an increase in hardness which had a direct influence on the tribological properties. An increase in coefficient of friction and decrease in wear rate subjected to the absorbed irradiation dose, was observed after irradiation. It portended a significant reduction of the tribological wear compared to the non-irradiated material. The improvement of tribological properties of PEEK under irradiation environment thus has become a key issue in this paper.
\end{abstract}

Keywords: tribology, PEEK, coefficient of friction, wear rate, gamma radiation

\section{Introduction}

Poly-ether-ether-ketone (PEEK) is one of the most promising polymers, a semi-crystalline thermoplastic. It is well known for its excellent mechanical properties. It can easily be processed in various shapes. Moreover, it processes high roughness and excellent wear resistance. It has good stability in both chemically active and radiation environments. Poly-ether-ether-ketone due to these properties is widely used for various applications as matrix for high performance composites, e.g. aerospace, nuclear and tribological (sliding bearings). Scientist have been extensively studied some engineered polymers for more possible applications e.g. nuclear power plant application as an obvious choice for replacing ceramic and metallic components. Radiation dose brings changes in mechanical and tribological properties of polymers. Gamma radiation effect on thermal properties of PEEK is increase of glass transition temperature as well as change of mechanical properties. Some works have concluded that exposure to gamma irradiation results in improvement in tribological and mechanical properties. In this paper it is studied the influence and radiation of PEEK on its useful properties before and after irradiation, against a plain carbon steel ring.

\section{Experimental}

\subsection{Materials}

Samples of PEEK were irradiated with gamma rays from a ${ }^{60} \mathrm{Co}$ source in a gamma chamber. The radiation was carried out by delivering radiation dose of 50 and $100 \mathrm{kGy}$. The mechanical and tribological properties of irradiated samples are compared to that of unirradiated samples.

\subsection{Microhardness measurement}

The microhardness of the specimens was determined by conducting four replicate measurements. Testing was performed by forcing a diamond indenter into the surface as a sample using a specified load of $1 \mathrm{~N}$

\footnotetext{
* Aneta Niemiec, MSc. Eng..: Faculty of Mechanical Engineering, Wroclaw University of Science and Technology, Lukasiewicza Street 4; 50-371 Wroclaw; PL, aneta.niemiec@pwr.edu.pl
} 
and a loading time of $5 \mathrm{~s}$. Microhardness testing with applied loads under $10 \mathrm{~N}$ is typically used for smaller samples. To find accurate results, at least four readings at different location of samples were determined and average value was reported.

\subsection{Tribological evaluation}

The friction and wear tests were conducted on pin-on-disc test rig presented in Fig. 1.

Flat ended cylindrical pins of irradiated and unirradiated PEEK with $8 \mathrm{~mm}$ diameter at contact were machined from rods. The polymer counter was made from carbon steel disc of $100 \mathrm{~mm}$ diameter. Disc was heat treated to achieve hardness value of 50-60 HRC and surface roughness (Ra) of $0.39 \mu \mathrm{m}$.

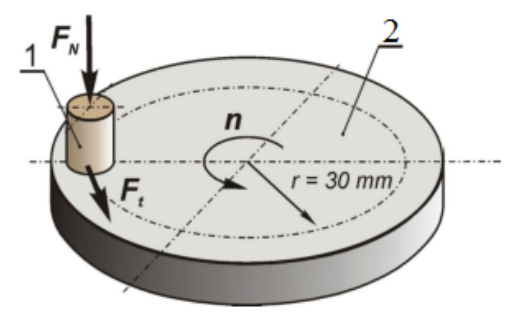

Fig. 1: Pin-on-disc rig: 1-pin, 2-country specimen.

PEEK pin sample was held by a pin holder against the rotating disc mounted on disc holder. A plain carbon steel ring (HRC 40-45) with diameter of $40 \mathrm{~mm}$ was used as the counterpart. Before each test polymer pins and steel disc were cleaned with alcohol. The tribological tests were carried out at sliding speeds of $0.5 \mathrm{~m} / \mathrm{s}$ and $1 \mathrm{~m} / \mathrm{s}$ and normal load of 50,100 and $150 \mathrm{~N}$. Diameter of pin at the contact was $8 \mathrm{~mm}$ and it was constant for all the test. Sliding distance of $1000 \mathrm{~m}$ was kept constant for all tests. During the test friction force was recorded continuously throughout the test. The coefficient of friction was calculated by taking into account the normal load applied and the friction force measured. Wear of the pin was evaluated by measuring volume loss after completing the test. Three replicate friction and wear tests were carried out, and the average values of the three replicate test results were presented. The relative error of the replicate friction and wear test data was $\pm 10 \%$.

\section{Results and discussion}

\subsection{Microhardness of PEEK}

The microhardness of irradiated and unirradiated PEEK is shown in tab.1. It is seen that the microhardness of polymer increases with increasing radiation dose. Radiation modification may resulte in crosslinking, which influences increase of hardness evaluation and is also expected to affect the tribological behaviour of the polymer.

Tab. 1: Variation of microhardness with radiation dose of PEEK

\begin{tabular}{cc}
\hline Radiation dose & Microhardness HV 0.1 \\
\hline $0 \mathrm{kGy}$ & $16,93 \pm 0,21$ \\
\hline $50 \mathrm{kGy}$ & $23,99 \pm 1,01$ \\
\hline $100 \mathrm{kGy}$ & $30,48 \pm 0,59$ \\
\hline
\end{tabular}




\subsection{Tribological properties}

Tribological properties of a material are one of the most important ones for machine exploitation. Figs. 2 and 3 show the variations of the coefficient of friction (COF) and wear volume loss of PEEK with change of radiation doses under various loads.
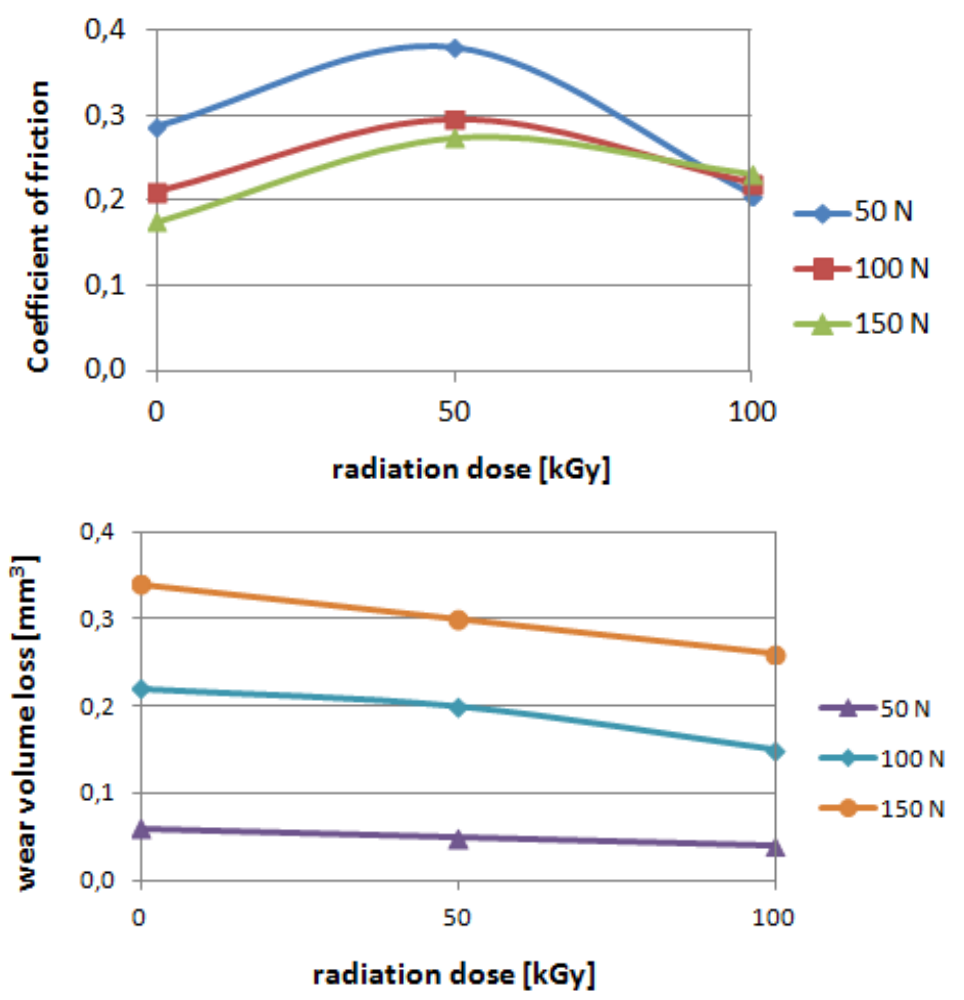

Fig. 2: The coefficient of friction and wear volume loss under various loads as functions of radiation dose of PEEK (sliding speed $0.5 \mathrm{~m} / \mathrm{s}$ )
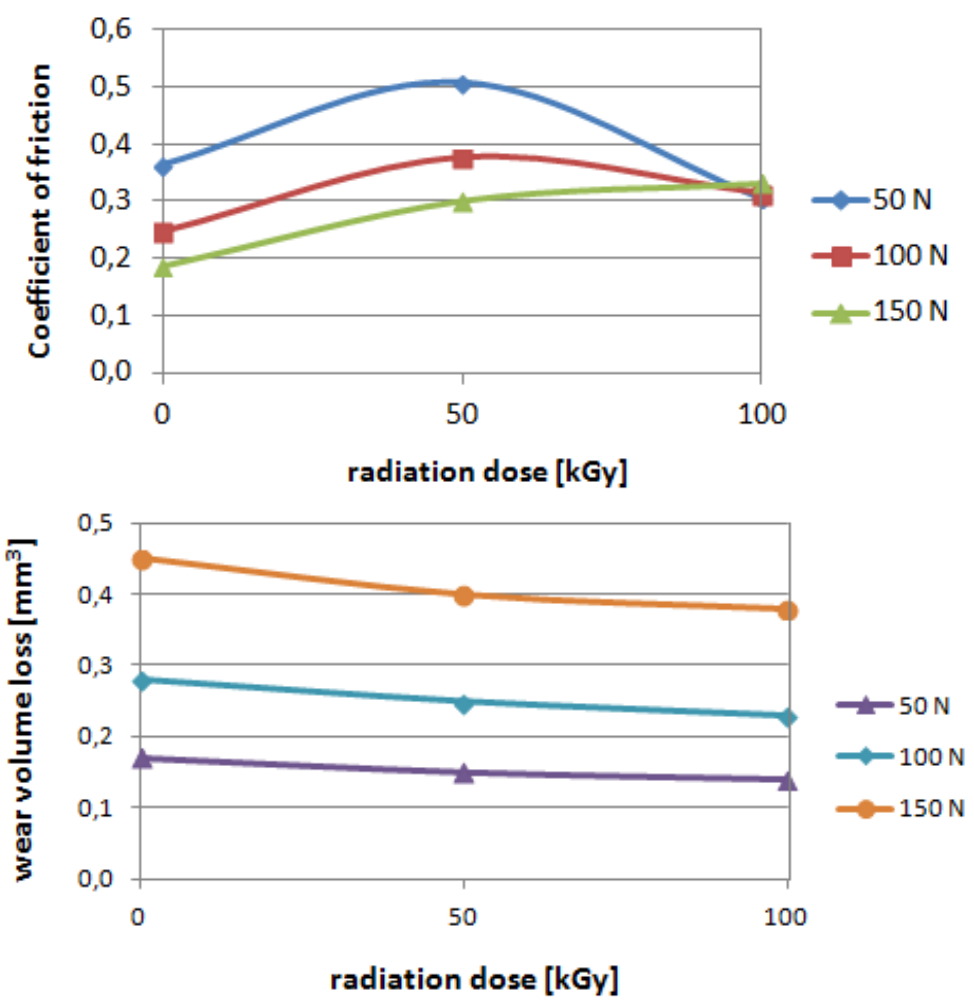

Fig. 3: The coefficient of friction and wear volume loss under various loads as functions of radiation dose of PEEK (sliding speed $1 \mathrm{~m} / \mathrm{s}$ ) 
Both parameters like load and sliding speed have effect on wear rate of irradiated and unirradiated samples. The lowest coefficient of friction at a load of $150 \mathrm{~N}$ is recorded for polymer unirradiated both for sliding speed of $0.5 \mathrm{~m} / \mathrm{s}$ and $1 \mathrm{~m} / \mathrm{s}$. However, for this specimen the wear volume loss is the highest. The highest COF was depicted by samples irradiated for $50 \mathrm{kGy}$ irradiation dose at each load and sliding speed. Starting with radiation dose of $50 \mathrm{kGy}$ lower wear volume loss can be observed and the lowest wear volume loss is registered at dose of $100 \mathrm{kGy}$. In combination with the friction coefficient and wear volume loss of PEEK, it is therefore rational to recommend the optimal radiation dose of $100 \mathrm{kGy}$, load of $50 \mathrm{~N}$ at $0.5 \mathrm{~m} / \mathrm{s}$. This observation conforms to the variation of the microhardness of the polymer. In general, increased hardness is responsible for increased wear resistance of material. In this work hardness of irradiated polymer is the highest at $100 \mathrm{kGy}$ of selected doses. In other words, the higher microhardness of PEEK (irradiated with dose of $100 \mathrm{kGy}$ and above) is advantageous to reduce the friction and antiwear ability of the irradiated polymer.

\section{Conclusions}

Gamma radiation has more and more applications. Materials like polymers are often exposed to this radiation which cause modifications in their useful properties. It is essential to measure those changes to verify if some crucial properties did not decrease and if material was not depolymerised, especially while those materials like PEEK have applications in aerospace, nuclear and medicine industries. What is more gamma radiation can be used to increase polymer properties e.g. to increase hardness and decrease wear rate. Those materials are used in demanding environment, e.g., with or without lubrication, high pressures, high sliding speeds, high loads. Exposure to gamma radiation of PEEK resulted in increase in hardness which is correlated with tribological properties. The most advantageous results were obtained for specimens irradiated with a dose of $100 \mathrm{kGy}$. Limited dose applied to polymers may cause some degradation, however initiate new bonds on the chain.

\section{References}

Celina, M., Gillen, K.T., Malone, G.M., Clough, R.L., Nelson W.H. (2001) Polymer materials and component evaluation in acidic-radiation environments. Radiation Physics and Chemistry, 62, pp. 153-161.

Jones, D.P., Leach, D.C., Moore, D.R. (1985) Mechanical properties of poly(ether-ether-ketone) for engineering applications. Polymer, 26, pp. 1385-1393.

Lawrence, F., Mishra, S., Mallika, C., Kamachi, U., Natarajan, R., Ponraju, D., Seshadri, S.K., Sampath Kumar, T.S. (2012) Degradation in thermal properties and morphology of poly-ether-ether ketone-alumina composites exposed to gamma radiation. Journal of Materials Engineering and Performance, 21, pp. 1266-1274.

Liu Jie, Xu, Davim, J.P., Cardoso, R. (2007) Prediction on tribological behaviour of composite PEEK-cf 30 using an artificial neural network. Journal of Materials Processing Technology, 189, pp. 374-378.

Quadrint, F., Squeo, E.A. (2007) Injection molding of bushes made of tribological PEEK composites. Polymer Letters, 12, pp. 817-823.

Sasuga, T., Hagiwara, M. (1987) Radiation deterioration of several aromatic polymers under oxidative conditions. Polymer, 28, pp. 1915-1921.

Sasuga, T., Kudoh, H. (2000) Ion irradiation effects on thermal and mechanical properties of poly(ether-etherketone) (PEEK). Polymer, 41, pp. 185-194.

Sokolski, P. (2017) On wear processes in pin joints in caterpillars of large-size working machines. Engineering Mechanics 2017, Brno University of Technology, Brno, pp. 910-913.

Sumer, M., Unal, H., Mimaroglu, A. (2008) Evaluation of tribological behaviour of PEEK and glass fibre reinforced PEEK composite under sliding and water lubricated conditions. Wear, 265, pp. 1061-1065.

Ziolkowska, J. (2017) Polyurethane coatings and methods of examination of their properties. Engineering Mechanics 2017, Brno University of Technology, Brno, pp. 1130-1133. 